\title{
Editorial
}

\section{Welcome to Atoms: A New Open Access Journal}

\section{James F. Babb}

Founding Editor-in-Chief, Institute for Theoretical Atomic, Molecular and Optical Physics, Harvard-Smithsonian Center for Astrophysics, 60 Garden Street, Cambridge, MA 02138, USA; E-Mail: jbabb@cfa.harvard.edu

Received: 14 December 2012 / Accepted: 14 December 2012 / Published: 17 December 2012

There is no doubt that it is an exciting time to be studying quantum properties of atoms, molecules, and nuclei. Increasingly deep connections between long-established fields: "atomic physics", "molecular physics", "chemical physics", "nuclear physics", "scattering theory", "nuclear magnetic resonance", "quantum optics", etc., are blurring old research labels. Atoms is a new open access journal with a broad scope that will aim to capture some of these exciting changes and developments, with a quantum flavor. The Editorial Board's collective expertise spans the fields involved and reflects the international communities active in these areas.

Our journal joins a sister publication now in its 17 th volume, Molecules, which covers synthetic organic chemistry and natural product chemistry.

Atoms welcomes research papers on experimental, computational, and theoretical topics, as well as the associated data, programs, or experimental details to be published as supplementary material. We also welcome your proposals for special issues or guest editorships.

So now that the new quantum era is here, we invite you to join in by sending your contributions falling within the broad scope of Atoms.

(C) 2013 by the authors; licensee MDPI, Basel, Switzerland. This article is an open access article distributed under the terms and conditions of the Creative Commons Attribution license (http://creativecommons.org/licenses/by/3.0/). 